\title{
A SOCIAL NETWORK ANALYSIS ON THE CULTURE OF HELPING IN HEALTH INSTITUTIONS
}

\author{
*Nursen Aydin \\ **S. Burak Bekaroglu \\ *Hatay Provincial Health Directorate \\ **Marmara University
}

\begin{abstract}
In this research, it is aimed to determine the network of helping and to compare the differences of helping relations of employees of three public health institutions in Istanbul. Participants were asked to give the names of the five people they requested the most for help through the questionnaire prepared by the researchers. Data was evaluated by social network analysis. Among health institutions, number of observations and number of helping ties were the highest in the health directorate. Network density was the highest in the hospitals union. The mean of ego networks data of the employees was higher in the health directorate. Between those who asked for help and those who were asked for help were homophily in terms of gender, age groups, educational level, hierarchical level, work experience and seniority at the health directorate and the hospital.
\end{abstract}

Keywords: Management of Health Institutions, Helping Networks, Social Network Analysis, Homophily, Multilevel Analysis.

\section{INTRODUCTION}

Businesses need to develop much more different abilities besides traditional organizational structures in order to be able to produce more efficient results and to be successful. In many studies it is reported that the successful and well carrying out of institutional support relations will have positive outcomes for the institutions. The real potential of the human power in businesses often emerge in a good environment of cooperation and collaboration. Especially in the service sector, managers need to develop a suitable business environment for cooperation and collaboration. As knowledge becomes increasingly specialized and distributed and as institutional infrastructures become more complex and interdependent, the demand for collaboration in both internal and external environments of the institutions also increases (Ansell and Gash, 2007). The term help is defined as giving assistance or support to benefit another person voluntarily by using his or her own power, resources, and capabilities without expecting anything for his or her own benefit when there is no obligation (TLI, 2016). Collaboration is a collective effort of people who work together to achieve mutual benefit as a result of their common actions. Cooperation can be seen as a union of people who come together in the context of the organizational environment to add value to the organization and produce useful output (Vacharkulksemsuk et al., 2011).

Any kind of relationship between individuals generate network of social ties (Guzeller et al., 2016). Friendship, cooperation, trade, information, communication, etc. between individuals, corporations or businesses are called social network. The history of social networks goes back to the first years of humanity. Since the time people have helped each other, it exists, even if it seems mostly invisible. Social networks consist of a collection of links between the groups of people (Hansen et al., 2010). Social network analysis began to emerge in the 1930s. However, it did not get much interest at that time. In the late 1990s, social network analysis began to be used extensively in the fields of physics and biology. In physics the data have been obtained through millions of the Internet-connected computers. Data on genetics and metabolic networks in biology have been produced by all genome studies (Freeman, 2011). In social systems, networking occurs naturally. The reciprocal friendships in social media accounts like the Facebook and the Twitter can be shown as examples of social networks (Tunali, 2016). Social network analysis in organizations is considered to be an effective method in order to reveal the effect of 
individual employees in the institution in question and to evaluate the network of relationships holistically that the working groups formed.

In this research, cooperation and collaboration relations of employees of Istanbul Provincial Health Directorate (Health Directorate), Istanbul Anatolian Southern Public Hospitals Union (Hospitals Union), and a public general acute care hospital (Hospital) affiliated with the Istanbul Anatolian Southern Public Hospitals Union were examined to determine network structures comparatively by using social network analysis and the differences between them were evaluated from the network organization point of view.

\section{LITERATURE REVIEW}

Any kind of relationship between individuals gives rise to the social networks (Guzeller et al., 2016). Relations of individuals, institutions or businesses, friendship, cooperation, trade, information, communication, etc. are called social network. The four significant features of social network analysis are able to reveal important connections between social actors, to record social relations that connects actors with each other through collecting and analyzing data, to reveal the patterns of these connections and to make graphs, and finally to find mathematical and computational models (Freeman, 2011). From the point of view of management science, the social network analysis is a tool that enables you to evaluate strategically important networks within an organization, to make invisible groups visible in interaction and to work important groups to facilitate effective collaboration. Perhaps the most important benefit of social network analysis is that managers focus attention on informal networks that may be critical to organizational effectiveness (Cross et al., 2002). Social network analysis has many different application areas. It can be applied in sociology, social psychology, anthropology, economics, information technology (Diestel, 2000).

In social network analysis; social networks' are structures in which individuals or groups are represented, and the sides are represented by a number of forms of social interaction, such as friendship, between people or groups (Newman, 2010). Individuals or groups in which social exchange takes place are called actors. It can be said that there is reciprocity if the relationship is between two or more actors. In the case of relationships involving three or more actors, the concept of network emerges. Networks connect both groups and individuals as actors (Emerson, 1976). There are binary, triple and click on the networks. The binary means that the number of nodes is two, and the triple means that the number of nodes is three. The subset of the nodes of a line is called the click (Tuzunturk, 2012). Reciprocity is one of the most basic, most important inclination in social interactions (Blau, 1964). On networking, saving information as a matrix and making graphics to visualize patterns is often very useful. The social network data consists of a square measurement line. In each cell on the line an relationship between the actors is explained (Hanneman and Riddle, 2005). The biggest difference between traditional and network data is that while traditional data focuses on actors and qualities, network analysis focuses on the relationship between actors and does not focus on individual actors and qualities (Hanneman and Riddle, 2005). In social network analysis, generally full network method and sampling method that is used in traditional researches, are carried out in selecting samples. When the sampling is selected, the population is determined based on the ego (usually the snowball method). In social network analysis in general, there are reciprocity, transitivity, structural equivalence, and clicks in network relations and structures. In social network analysis, analyzes are made according to the actors (knots) or the whole network. According to the properties of the nodes, degree, proximity, betweenness, eigenvector centrality are measured. According to the whole network, centralization (degree, betweenness, proximity, eigenvector, etc.), clustering coefficient, homophilic, modularity, diameter measurements are made (Denny, 2014).

Sociology, physics sciences as well as health sciences social network analysis studies have been done. Provan and Sebastian (1998), in their study of three different healthcare providers, they conduct a clique analysis to explain the network activity that they got through the questionnaire and interview. In the framework of the analysis, they measured the size of cliques, dyadic links, and network density, and graphically displayed the results. Behrendt et al., (2014) conducted research on the institutional social networks of health workers and Perkins et al., (2015) on natural social networks in low and middleincome countries. Amabile et al., (2014) conducted a research on cooperation in a design firm called Ideo. In the article, titled Ideo's Culture of Helping, the firm Ideo is defined as a help friendly company. The approaches of the managers about employees helping each other and to do this naturally and the 
accessibility, competence, and reliability of the employees who asked for the help were questioned. As a result of the research, it was shown that the help was asked from the most reliable and accessible staff instead of asking to technically competent staff, and the successful cooperation experience increased morale and job satisfaction. Below are the data and methodology in part 3, findings and discussions in part 4, and finally the concluiion.

\section{DATA AND METHODOLOGY}

The study includes all the employees who accepted to participate from Istanbul Provincial Health Directorate (274 persons), Istanbul Anatolian Southern Hospitals Union (81 persons), and medical and surgical clinics as well as administrative units of a hospital (147 persons) affiliated with Istanbul Anatolian Southern Hospitals Union. Data obtained via a survey questionnaire formed by the researchers which includes some demographic information and the names of other employees in the institution from whom the respondent requested help frequently. Social network analysis was applied by using UCINET software for windows (Borgatti et al., 2002) and NetDraw software was used to draw network maps (Borgatti, 2002). Statistical analyses were applied by using IBM-SPSS version 24 . The data used in the analyses were obtained by $417 \times 417$ matrices in the health directorate, $117 \times 117$ matrices in the hospitals union, and $235 \times 235$ matrices in the hospital and by creating an attribute file for all three institutions. Data and cooperation maps created within the scope of social network analysis were made separately for the three public institutions.

\section{FINDINGS AND DISCUSSIONS}

Table 1 shows the descriptive statistics of the employees involved in the survey. Those who are undefined in the health directorate are actors who are not filled out the questionnaire or whose names are written as persons who are requested for assistance from outside the institution but whose data for the attribute file cannot be reached.

Table 1. Descriptive statistics of social network.

\begin{tabular}{lccc}
\hline Variables & Health Directorate & Hospitals Union & Hospital \\
\hline N of participants & 274 & 81 & 147 \\
N of non-participants but help requested & 143 & 36 & 88 \\
N of nodes & 417 & 117 & 235 \\
Gender & & & \\
$\quad$ Male & 254 & 74 & 126 \\
$\quad$ Female & 163 & 43 & 109 \\
Hierarchical levels & & & \\
$\quad$ Top management & 13 & 5 & 10 \\
Middle management & 17 & 23 & 20 \\
Lower management & 38 & 0 & 26 \\
Non-managerial employees & 304 & 89 & 179 \\
$\quad$ Unidentified & 45 & 0 & 0 \\
\hline
\end{tabular}

Table 2 shows the basic data of social network analysis conducted within the scope of the research such as network densities, transitivity rates, ties reciprocality, averages etc. It was seen that the maximum number of nodes (417) and the maximum value of in-degree (23) was in the health directorate when the table below is examined according to the institutions.

When the centrality degrees' tie means, internal and external network centrality ratios in the health institutions was examined, it was seen that the health directorate was $2.197,5.01 \%$ and $0.68 \%$, the hospitals union was $2.581,2.10 \%$ and $11.67 \%$, and the hospital was $2.336,1.14 \%$ and $4.58 \%$, respectively. When the standard deviation values was examined, the most homogeneous institution $(\mathrm{SD}=$ 0.098) and the institution with the largest number of helping ties (number of ties $=916$ ) was the health directorate.

The overall graph clustering coefficient was highest at the hospital $(0.270)$. The overall graph clustering coefficient is the average of the neighbors' density of all actors in the network. The weighted overall 
graph clustering coefficient weights the densities in proportion to the neighborhood dimensions. That is, actors with larger neighborhood groups gain more weight when their average intensity is calculated. Because large graphs are generally less dense than small graphs, the weighted average neighbor density (or clustering coefficient) is often lower than the unweighted version (Hanneman and Riddle, 2005).

When Krackhardt GTD variables was examined in the table, connectedness and the minimum upper bound values (LUB) was 1 in three institutions and the hierarchy was 0 . When network transitivity of the health institutions was analyzed, the results $10.88 \%$ in the health directorate, $14.51 \%$ in the hospitals union and $14.46 \%$ in the hospital were obtained. According to the above data, among the health institutions participating in the research, the hospitals union had the highest rate of network transitivity with $14.51 \%$. Moreover, the hospitals union had the highest rate of $50.75 \%$ of transitivity ratios in triadic groups. The densest network (0.040) in helping network belonged to the hospitals union.

All actors with any tie had 19\% in the health directorate, $23 \%$ in the hospitals union and $21 \%$ in the hospital among all possible ties. All actor pairs with any tie had $11 \%$ in the health directorate, $13 \%$ in the hospitals union and $12 \%$ in the hospital. When the transitivity indicators of health institutions were examined, the highest rate was observed in the hospitals union (14.51\%). All triadic groups that are owned were at most in the health directorate (25655989).

Table 2. Social network analysis descriptive statistics.

\begin{tabular}{|c|c|c|c|}
\hline Variables & Health Directorate & Hospitals Union & Hospital \\
\hline \multicolumn{4}{|l|}{ Freeman’s degree centrality measures } \\
\hline $\mathrm{N}$ of nodes & 417.000 & 117.000 & 235.000 \\
\hline Min. in-degree & 0.000 & 0.000 & 0.000 \\
\hline Max. in-degree & 23.000 & 16.000 & 13.000 \\
\hline Mean & 2.197 & 2.581 & 2.336 \\
\hline Sum & 916.000 & 302.000 & 235.000 \\
\hline \% of network centralization (out-degree) & 0.676 & 2.103 & 1.143 \\
\hline$\%$ of network centralization (in-degree) & 5.013 & 11.668 & 4.577 \\
\hline \multicolumn{4}{|l|}{ Density/average matrix value } \\
\hline $\mathrm{N}$ of ties & 916.000 & 302.000 & 549.000 \\
\hline Density & 0.010 & 0.040 & 0.022 \\
\hline Standard deviation & 0.098 & 0.197 & 0.148 \\
\hline Avg. degree & 2.197 & 2.581 & 2.336 \\
\hline Alpha & 0.803 & 0.831 & 0.843 \\
\hline \multicolumn{4}{|l|}{ Clustering coefficients } \\
\hline Overall graph clustering coefficient & 0.248 & 0.256 & 0.270 \\
\hline Weighted overall graph clustering coefficient & 0.166 & 0.197 & 0.198 \\
\hline \multicolumn{4}{|l|}{ Krackhardt GTD measures } \\
\hline Connectedness & 1.000 & 1.000 & 1.000 \\
\hline Hierarchy & 0.000 & 0.000 & 0.000 \\
\hline Efficiency & 0.427 & 0.459 & 0.383 \\
\hline LUB & 1.000 & 1.000 & 1.000 \\
\hline \multicolumn{4}{|l|}{ Reciprocity } \\
\hline Reciprocal arcs & 176.000 & 70.000 & 116.000 \\
\hline Unreciprocal arcs & 740.000 & 232.000 & 433.000 \\
\hline All arcs & 916.000 & 302.000 & 549.000 \\
\hline Arc reciprocity & 0.192 & 0.232 & 0.211 \\
\hline Symmetric dyads & 88.000 & 35.000 & 58.000 \\
\hline Asymmetric dyads & 740.000 & 232.000 & 433.000 \\
\hline All dyads & 828.000 & 267.000 & 491.000 \\
\hline Dyad-based reciprocity & 0.106 & 0.131 & 0.118 \\
\hline \multicolumn{4}{|l|}{ Transitivity } \\
\hline $\mathrm{N}$ of non-vacuous transitive ordered triples & 742.000 & 272.000 & 439.000 \\
\hline $\mathrm{N}$ of triples of all kinds & 25655989.000 & 589563.000 & 3541568.000 \\
\hline $\mathrm{N}$ of triples in which $\mathrm{i} \rightarrow \mathrm{j}$ and $\mathrm{j} \rightarrow \mathrm{k}$ & 1805.000 & 536.000 & 908.000 \\
\hline $\mathrm{N}$ of triangles with at least 2 legs & 6821.000 & 1875.000 & 3037.000 \\
\hline $\mathrm{N}$ of triangles with 3 legs & 742.000 & 272.000 & 439.000 \\
\hline$\%$ of all ordered triples & 0.000 & 0.050 & 0.010 \\
\hline $\begin{array}{l}\% \text { of ordered triples in which } \mathrm{i} \rightarrow \mathrm{j} \text { and } \mathrm{j} \rightarrow \mathrm{k} \text { that } \\
\text { are transitive }\end{array}$ & 41.110 & 50.750 & 48.350 \\
\hline$\%$ of triangles with at least 2 legs that have 3 legs & 10.880 & 14.510 & 14.460 \\
\hline $\mathrm{N}$ of triples with all 3 legs & 123.000 & 45.000 & 73.000 \\
\hline $\mathrm{N}$ of triples with at least 2 legs & 1136.000 & 312.000 & 506.000 \\
\hline Network transitivity (\%) & 10.878 & 14.507 & 14.455 \\
\hline
\end{tabular}


Below, there are NetDraw graphical presentations of helping and collaboration networks of the health institutions researched. The network maps were created for three different institutions through interworking of the network matrix file prepared for the institutions with the attribute data files composed of units and hierarchical levels that created for the same actors. A variety of colors and shapes were added to units and hierarchical levels (Appendix) in order to transmit information and facilitate visibility in the best way possible through helping and collaboration network maps prepared from the data obtained within the scope of the research.

According to the health directorate's helping and collaboration map (Figure 1), the network map showing the helping structure of the units in the health directorate and the actors in the units does not exactly coincide with each other. Particularly in the branches of Accrual and Financial Affairs, Administrative Affairs, and Human Resources helping took place both within the unit and between the units. There were relatively more helping relations within the branch in Public Inpatient Health Services. Generally, subgroups were formed in the branches. It appeared that there were isolated groups that are totally disconnected from the main group and a large number of pendants. It was determined that mid-level and senior manager-centered (i.e. hierarchical) networks existed in Accrual and Financial Affairs, Administrative Affairs, and Human Resources branches and those middle and senior managers were asked for assistance above the average. Also, in other branches and isolated groups, there was a horizontal level helping and mid-level managers and colleagues have come to the forefront in helping. The actors who were most asked for help were at the center of the main mass.

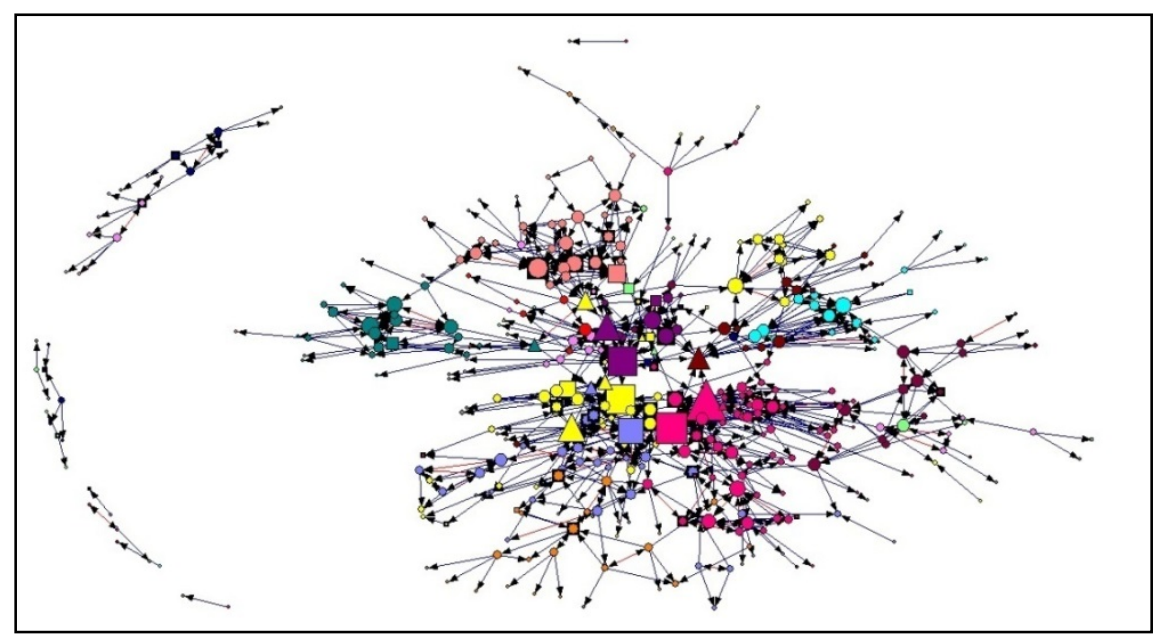

Fig. 1. Helping network map of Health Directorate.

In general, the employees of the branch had helping relations both in their own branches and with other branch employees. This situation was seen in both with professional hierarchical superiors of employees and with employees of the same hierarchical level. Some actors had undertaken the role of brokerage in maintaining the relation of helping between the main mass and the subgroups of the branches. When reciprocality of helping relations were examined in the health directorate, it was seen that the relationships were less reciprocal and usually one-sided.

In the hospitals union, the network map showing the collaboration structure of the units and the actors in the units exactly coincides with each other. According to the map of helping and collaboration of the hospitals union (Figure 2), it was clearly seen that helping has taken place within the units not between the departments. 


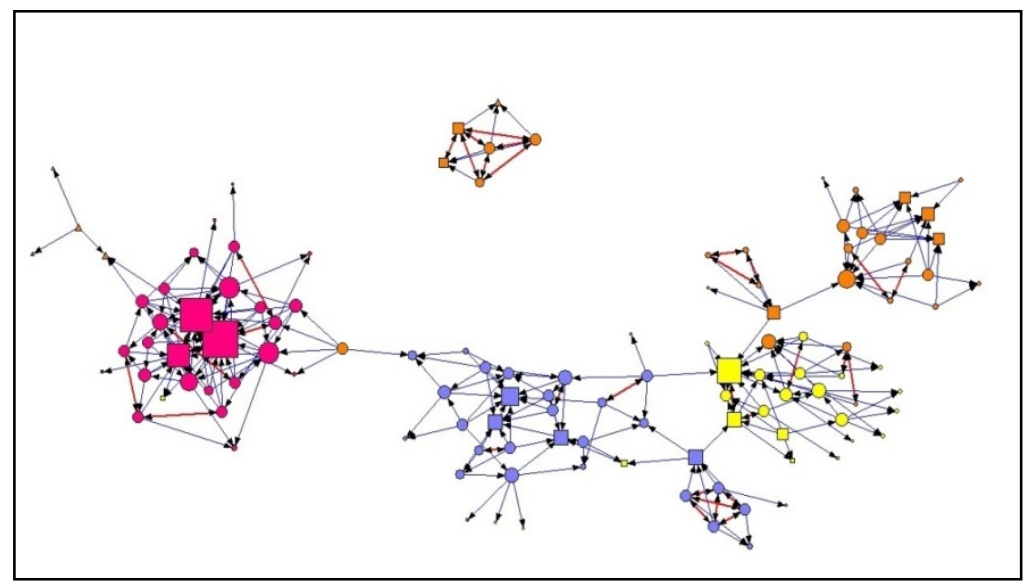

Fig. 2. Helping network map of Hospitals Union.

A small number of people built up a tie between units. It appeared that there were four small groups that were pendants. One of the pendants was the group where senior managers of the institution were located. There was a network of specialists (mid-level managers) centered in all units and it was more intensive in the departments of Financial Services and Administrative Services. When reciprocality of helping relations were examined in the hospitals union, it was seen that the relationships were less reciprocal and usually one-sided, as was seen in the health directorate.

In the hospital, the network map showing the helping relations of the actors in the units and position of the units exactly coincides with each other. According to the map of helping and collaboration network of the hospital (Figure 3), it was seen helping relations concentrated within the units especially in the clinical units, and there was less helping relationship between the Hospital Administration and the clinics. There were four isolated groups and a large number of pendants. It was seen that the Hospital Administration formed mid-level and senior manager-centered helping relations, that is, a hierarchical network of helping and these mid-level and senior managers were asked for help above the average. Moreover, in the clinics and isolated groups, helping occurred at the horizontal level and clinical chefs and colleagues have come to the forefront in helping.

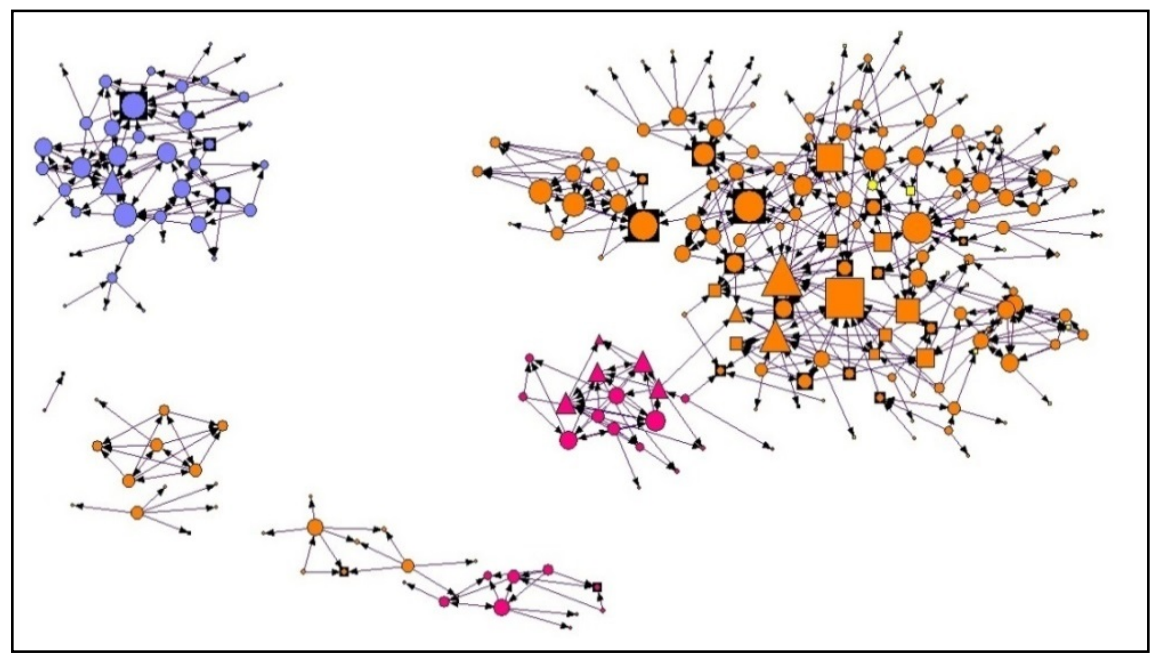

Fig. 3. Helping network map of the hospital.

In general, the actors who were most asked for help were at the center of the groups at the same time. In all units, employees did not have any helping relations with the employees from other units. The helping relations with other units were generally observed between clinical chefs and senior managers of Hospital Administration. The helping relations between surgical clinic and the administrative units was established 
through two actors. The internal clinic was completely isolated in helping and cooperated in itself When reciprocality of helping relations were examined in the hospital, it was seen that the relationships were less reciprocal and usually one-sided.

The attributes graphs as to coordinates of the three separate institutions are shown below (Figure 4, Figure 5, and Figure 6). In these graphs, units were loaded on $\mathrm{x}$-axis and hierarchical levels were loaded on $\mathrm{y}$ axis. In order to visualize the nodes and make the graph easier to understand, the nodes where the people are located were repositioned using the drag and drop method and the overlapping nodes were slightly opened.

When the helping maps of institutions were examined according to units, helping relations were observed intensely within the units of all three institutions. Also, apart from the health directorate, it was seen that in other two institutions, there was very little helping between the units and helping relations were provided by a few brokerage actors. Helping in the health directorate was widespread among employees in all hierarchical levels. There was horizontal helping network especially in clinics in the hospital and horizontal and vertical helping in the hospital administration. In the hospitals union, mid-level managers (experts) was at the center of helping.

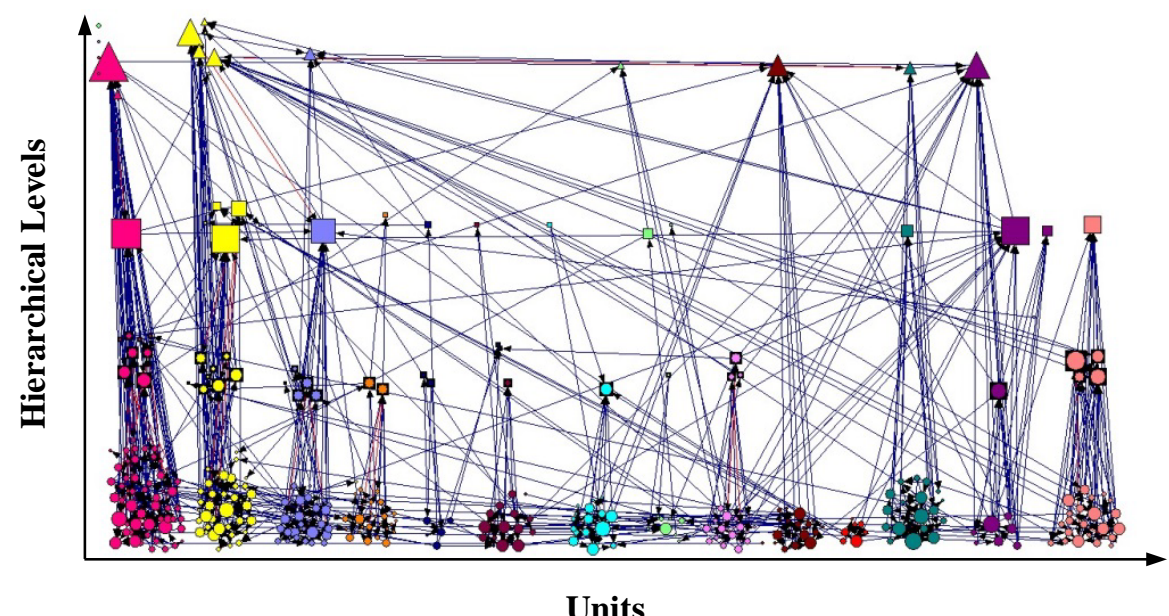

Fig. 4. Hierarchical levels and units based helping network map of Health Directorate.

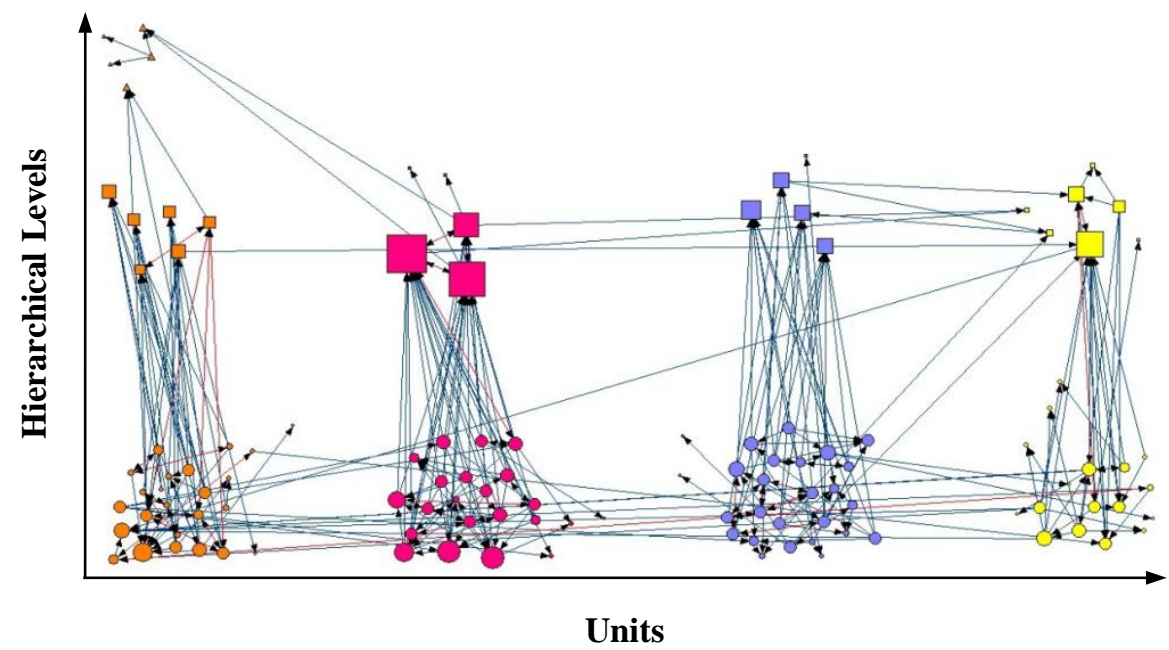

Fig. 5. Hierarchical levels and units based helping network map of Hospitals Union. 


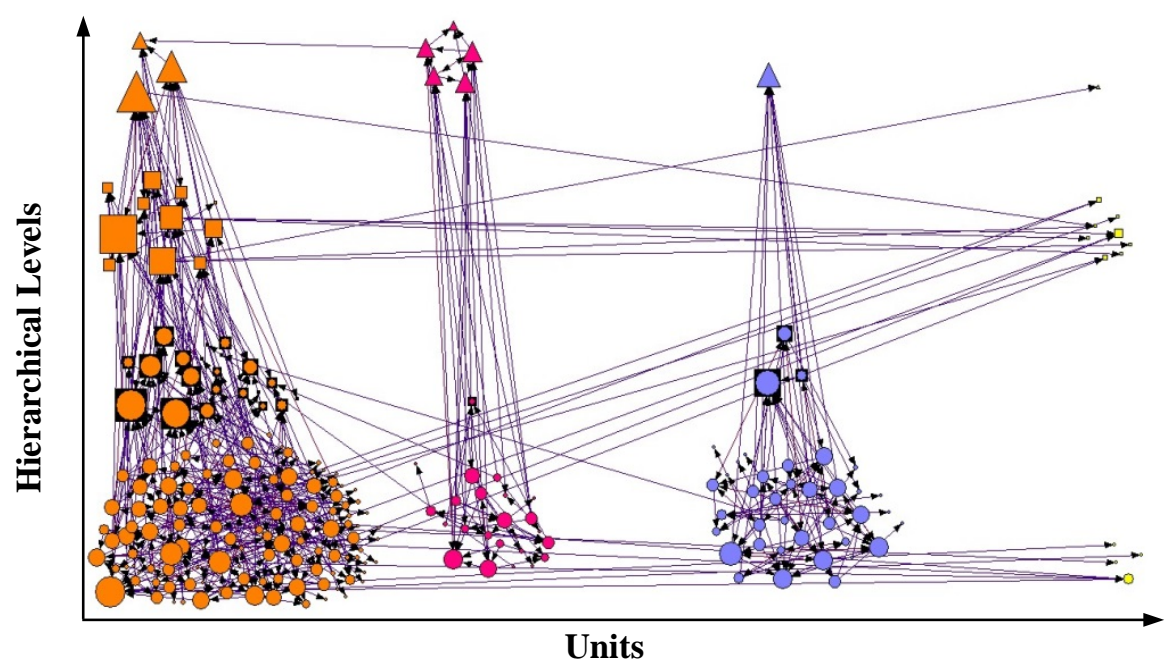

Fig. 6. Hierarchical levels and units based helping network map of the Hospital.

Results of variance analysis (ANOVA) in which Tukey HSD used as a post-hoc test to compare social network variables on helping relationships of the health institutions is as follows (Table 3).

Table 3. Social network analysis ANOVA table.

\begin{tabular}{|c|c|c|c|c|c|c|c|c|}
\hline \multirow[b]{2}{*}{ Variables } & \multicolumn{2}{|c|}{ Health Directorate } & \multicolumn{2}{|c|}{ Hospitals Union } & \multicolumn{2}{|c|}{ Hospital } & \multirow[b]{2}{*}{$\mathbf{F}$} & \multirow[b]{2}{*}{$\mathbf{P}$} \\
\hline & Mean & $(\mathrm{SD})$ & Mean & $(\mathrm{SD})$ & Mean & $(\mathrm{SD})$ & & \\
\hline \multicolumn{9}{|c|}{ Multiple centrality measures } \\
\hline Out-degree & 2.488 & $(2.208)$ & 2.493 & $(2.137)$ & 2.457 & $(2.140)$ & 0.036 & 0.964 \\
\hline In-degree & 6.051 & $(5.448)$ & 5.256 & $(4.042)$ & 4.620 & (3.178) & 14.850 & 0.000 \\
\hline Out-closeness & 6475.008 & (203.792) & 1412.872 & (95.632) & 2048.090 & $(58.324)$ & 177630.285 & 0.000 \\
\hline In-closeness & 6240.563 & $(536.525)$ & 1369.675 & (77.618) & 2000.908 & $(103.160)$ & 25889.559 & 0.000 \\
\hline Betweenness & 119.977 & $(274.735)$ & 27.021 & (44.767) & 34.512 & $(69.542)$ & 37.541 & 0.000 \\
\hline \multicolumn{9}{|c|}{ Ego network density measures } \\
\hline Size & 7.664 & (5.737) & 6.788 & $(4.327)$ & 6.314 & $(3.632)$ & 11.879 & 0.000 \\
\hline Ties & 9.833 & (8.949) & 9.460 & (10.918) & 7.406 & (6.322) & 12.359 & 0.000 \\
\hline Pairs & 83.943 & (134.499) & 57.949 & (81.025) & 46.723 & $(54.442)$ & 19.833 & 0.000 \\
\hline Density & 21.941 & (20.465) & 23.741 & (22.376) & 22.986 & $(17.970)$ & 0.947 & 0.388 \\
\hline Avg. distances & 0.054 & $(0.240)$ & 0.506 & $(0.155)$ & 0.041 & $(0.211)$ & 494.445 & 0.000 \\
\hline Diameter & 0.072 & $(0.349)$ & 0.515 & (0.209) & 0.055 & $(0.298)$ & 234.117 & 0.000 \\
\hline Reach efficiency & 59.119 & (20.901) & 51.643 & (19.192) & 58.473 & (21.223) & 13.832 & 0.000 \\
\hline Broker & 37.085 & (63.907) & 24.368 & (35.319) & 19.600 & (25.016) & 20.084 & 0.000 \\
\hline Ego betweenness & 11.024 & $(24.580)$ & 9.387 & (18.834) & 7.386 & (11.809) & 4.828 & 0.008 \\
\hline
\end{tabular}

When the ego network data of the employees who are asked for help was examined separately according to health institutions, the average of in-degree variable of the health directorate was higher both than the hospital $1.430(\mathrm{SE}=0.265, \mathrm{p}=0.000)$ and the hospitals union $0.795(\mathrm{SE}=0.323, \mathrm{p}=0.000)$. Outcloseness variable on an average of health directorate was higher than the hospitals union 5062.136 ( $\mathrm{SE}=$ 10.798, $\mathrm{p}=0.000)$ and the hospital $4426.918(\mathrm{SE}=8.874, \mathrm{p}=0.000)$, and also the hospital also was found to be higher than the hospitals union 635.218 ( $\mathrm{SE}=11.574, \mathrm{p}=0.000)$. In-closeness variable on an average of health directorate was higher than the hospitals union $4870.888(\mathrm{SE}=27.148, \mathrm{p}=0.000)$ and 
the hospital 4239.655 ( $\mathrm{SE}=22.308, \mathrm{p}=0.000$ ), and also the hospital was found to be higher than the health directorate $631.233(\mathrm{SE}=29.098, \mathrm{p}=0.000$ ). The average of betweenness variable was found to be higher in the health directorate than in the hospitals union $92.956(\mathrm{SE}=14.031, \mathrm{p}=0.000)$ and in the hospital $85.465(\mathrm{SE}=11.529, \mathrm{p}=0.000)$. The average of size variable was found to be higher in the health directorate than in the hospital $1.349(\mathrm{SE}=0.284, \mathrm{p}=0.000)$ and in the hospitals union 0.875 (SE $=0.345, \mathrm{p}=0.030)$. The average of ties variable was found to be higher $2.427(\mathrm{SE}=0.498, \mathrm{p}=0.000)$ in the health directorate than in the hospital 2.054 ( $\mathrm{SE}=0.650, \mathrm{p}=0.005)$, and it was also found to be higher in the hospitals union than in the hospital 2.054 ( $\mathrm{SE}=0.650, \mathrm{p}=0.005)$. Pairs variable on an average of the health directorate was higher than the hospitals union $25.994(\mathrm{SE}=7.445, \mathrm{p}=0.001)$ and the hospital 37.220 ( $\mathrm{SE}=6.118, \mathrm{p}=0.000)$. Average distance variable on an average of the hospitals union was higher than the hospital $0.465(\mathrm{SE}=0.016, \mathrm{p}=0.000)$ and the health directorate $0.451(\mathrm{SE}=0.015, \mathrm{p}$ $=0.000)$. Diameter variable on an average was found to be higher in the hospitals union than in the hospital $0.460(\mathrm{SE}=0.024, \mathrm{p}=0.000)$ and than in the health directorate $0.443(\mathrm{SE}=0.022, \mathrm{p}=0.000)$. Reach Efficiency variable on an average was found to be higher in the health directorate than in the hospitals union 7.477 ( $\mathrm{SE}=1.458, \mathrm{p}=0.000$ ), and also it was found to be higher in the hospital than in the hospitals union 6.830 ( $\mathrm{SE}=1.562, \mathrm{p}=0.000$ ). The average of broker variable of the health directorate was higher than the hospital $17.485(\mathrm{SE}=2.875, \mathrm{p}=0.000)$ and the hospitals union $12.716(\mathrm{SE}=3.498, \mathrm{p}$ $=0.001$ ). The average of ego betweenness variable was found to be higher in the health directorate than in the hospital $3.638(\mathrm{SE}=1.172, \mathrm{p}=0.006)$.

Chi-square tests employed to examine whether there was homophiliy in terms of gender between the employees who asked for help and the ones whom they asked for help, showed statistically significant relationships for whole sample. The employees in both gender who asked for help mainly asked male employees for help. Male employees who asked for help requested help from male employees at the ratio of $68.4 \%$ while female employees who asked for help requested help from male employees at the ratio of $55.3 \%\left(\chi^{2}=24.72, p=0.000\right)$. Female employees who asked for help showed heterophilic characteristics in terms of the gender of the employee from whom they asked for help whereas male employees who asked for help showed homophilic characteristics in terms of the gender of the employee from whom they asked for help. There was also a significant difference in similarity according to the gender when the institutions was examined one by one (for the health directorate $\chi^{2}=5.86, p=0.016$; for the hospitals union $\chi^{2}=11.42, \mathrm{p}=0.001$; and for the hospital $\chi^{2}=12.39$, $\mathrm{p}=0.000$ ).

When age was examined, a weak correlation between the employees who asked for help and the employees who were asked for help was found in the health directorate $(r=0.211, p=0.000)$, and in the hospital $(r=0.095, p=0.036)$. There was no significant correlation in the hospitals union $(p>0.05)$. When the similarity according to age categories of the employees was examined in health institutions, significant differences were found in the health directorate $\left(\chi^{2}=37.70, \mathrm{p}=0.000\right)$, and the hospital $\left(\chi^{2}=\right.$ $11.70, p=0.020)$. No statistically significant difference was found in the hospitals union ( $p>0.05)$. In the health directorate, employees under 30 years of age asked for help from the employees under 30 years of age (19.4\%) at least and from 30 years old and above (30-39 years $60.0 \%$ and 40 years old and above 20.6\%) at most. There is no significant difference in the 30-39 age group of employees. In the health directorate, employees under 30 years of age were heterophilic. Employees in all age groups who asked for help from the employees under 30 years of age (8.7\%) at least and 30-39 age group (62.2\%) at most. In the hospital, employees under the age of 30 years old who asked for help from the employees under the age of 30 years old (10.8\%) at least and 30 years old and above (30-39 years old $68.7 \%$ and 40 years old and above 20.5\%) at most. There was no significant difference in the 30-39 age group of employees. In the hospital, employees under the age of 30 years again were heterophilic. The employees in the 30-39 age group asked for help from the employees aged 30-39 years (62.7\%) at most. The employees 40 years of age and above asked for help from the employees under 30 years of age (1.9\%) at least and 30 years of age and above (30-39 years $65.2 \%$ and 40 years old and above $32.9 \%$ ) at most. In the hospital, employees of all age groups asked for help from under the age of 30 years old (6.5\%) at least and 30-39 age group (64.5\%) at most.

According to the marital status of the employees who were asked for help, there was no statistically significant relationship between the employees who asked for help and the employees who were asked for help $(p>0.05)$. There was a significant difference in similarity according to education level in the health 
directorate $\left(\chi^{2}=21.65, \mathrm{p}=0.000\right)$ and in the hospital $\left(\chi^{2}=73.23, \mathrm{p}=0.000\right)$. No statistically significant difference was found in the hospitals union $(p>0.05)$. The employees with low-level of education asked for help from the employees with low-level of education (42.5\%) at most in the health directorate. There is no significant difference in employees with mid-level of education. The employees with high-level of education asked for help from the employees with high-level of education (42.7\%) at most. The employees with mid-level education were heterophilic while the employees with low and high-level education were homophilic. The employees with high-level of education were less homophilic because they also asked for help from the employees with mid-level education. In the hospital, the employees with low-level education asked for help from the employees with low-level of education (50.9\%) at most. The employees with mid-level education asked for help from employees with mid-level education (19.2\%) at least. The employees with high-level of education asked for help from the employees with high-level of education $(75.3 \%)$ at most. The employees with mid-level of education were heterophilic while the employees with low and high-level of education were homophilic. The employees with high-level of education in the hospital were more homophilic than the employees with high-level of education in the health directorate.

In the three health institutions, there was a significant similarity according to hierarchical level of the employees who asked for help and the employees who were asked for (for the health directorate $\chi^{2}=$ $24.94 \mathrm{p}=0.003$; for the hospitals union $\chi^{2}=21.28 \mathrm{p}=0.000$; and for the hospital $\chi^{2}=107.96 \mathrm{p}=0.000$ ). Those who asked for help at all levels often asked help from the employees below their own hierarchical level. For example, senior managers in the health directorate (57.1\%), mid-level managers in the hospitals union (68.4\%), and in the hospital (50.0\%) asked for help from non-managerial employees.

According to the job experience, a weak correlation was found between the employees who asked for help and the employees who were asked for help in the health directorate $(r=0.144, p=0.000)$, and in the hospital $(r=0.108, p=0.017)$. No significant correlation was found in the hospitals union ( $p>0.05)$. According to similarity in categories of job experience in health institutions, significant differences were found in the health directorate $\left(\chi^{2}=17.72, \mathrm{p}=0.001\right)$, and in the hospital $\left(\chi^{2}=10.50, \mathrm{p}=0.033\right)$. No statistically significant difference was found in the hospitals union ( $>0.05)$. The employees who work in the health directorate for 10-19 years asked help from the employees who work for 10-19 years (54.2\%) at most. In health directorate, the employees who work for 10-19 years were homophilic. The employees who work for 10 years and under, and the employees who work for 20 years and above asked for help from the employees who work for 10 years and above. They asked most for help from the employees who work for 10-19 years (57.4\%), next, from the employees who work for 20 years (25\%). In the hospital, the employees who work for 10-19 years asked most for help from the employees who worked for 10-19 years (60.6\%). In hospital, the employees who worked for 10-19 years were homophilic. The employees who work for 20 years and above asked for help from the employees who work for 10 years and above. They asked most for help from the employees who work for 10-19 years (60.6\%), next, from the employees who work for 20 years (21.8\%).

According to the tenure, there was a significant weak correlation between the employees who asked for help and the employees who were asked for help only in the health directorate $(r=0.134, p=0.000)$. There was no significant correlation in the hospital and the hospitals union $(\mathrm{p}>0.05)$. There was no significant difference in three health institutions when the similarity in the categories of tenure of employees were compared $(\mathrm{p}>0.05)$.

\section{CONCLUSION}

Istanbul Provincial Health Directorate, on behalf of the Ministry of Health, determines policies, establishes strategies, and conducts audit activities for the health service delivery in Istanbul. As a service unit, the hospital carries out health services provision within the framework of these predetermined policies and strategies. Istanbul Anatolian Southern Hospitals Union is an institution responsible for providing data and information flow between Istanbul Provincial Health Directorate and the hospital and carrying out the coordination activities. These three institutions are institutions that have differentiated functions in the process of health care delivery and at the same time complement each other in terms of their activities. For this reason, the social network variables such as density, degree, betweenness, pairs, etc. of these institutions were examined and comparisons were made between the institutions. In our 
research, network maps showing the relationships between the employees of three health institutions in Istanbul were drawn up and social network analyses were conducted. Administrators can use this data which was obtained from the network analyses to learn the key components of the networks, key actors and characteristics, and basic motivations of employees (Behrendt et al., 2014).

The health directorate has the highest number of observations in the three health institutions researched. The centrality ratios of the health institutions are not very low when the average number of ties, internal and external network centrality ratios, network density are taken into consideration.

In Herz and Petermann (2017) ego-centric social network analysis, network size is 2.570, the network density is 0.718 and the network average is 1.764. In Matook's (2013) study, the in-degree variance for 13 target items ranged from 3.7 to 6.6. Ouelleta et al., (2017) stated that network size was 83, density was 0.13, clustering coefficient was 0.42 and average degree was11.0. In Molano and Polo's (2015) study of 35 actors, in-degree variable ranged from 7 to 9 with a mean in-degree of 3.025, a maximum in degree of 9.000 and a sum of 121.000 .

The health directorate is the most homogenous institution in terms of the number of helping ties according to standard deviations. This may be related to the fact that the number of actors in the health directorate is high. On the other hand, because health directorate is the governing body that sets policy, develops strategies and conducts auditing activities, it may have led to the establishment of more intensive helping relationships among employees, as they need to make quick and accurate decisions while coordinating provincial health services delivery.

The most intense network in helping matrices is available at the hospitals union. However, the number of actors of the hospitals union $(n=117)$ is the lowest among the other institutions. Helping network density of the institutions can be perceived relatively low. However, according to the nature of the work, each actor could specify 5 actors' names (not all names on the network) for which he asked for help. In this study, the number of actors in health institutions is relatively higher than the other real social network researches in the literature. When the research structure and the number of actors of the institutions are taken into account, the intensity of the helping matrices is not low. The concentration of large groups is relatively small compared to small groups (Carrington, 2014; Faust, 2006). In addition, the presence of actors whose nodes were not filled due to not participating in the study at all three institutions may have affected network density.

The size of social networks varies according to the nature of the network and the scope of the research. The size of networks such as the film actors cooperation network, the scientific cooperation network, the network of company executives etc. varies between 573 and 1520251 (Newman, 2003; Ramasco et al., 2004). The grade average is $\mathrm{k}=2.56$ in distance education networks, $\mathrm{k}=3.15$ in complex networks, and $\mathrm{k}$ $=1.58$ in information science networks (Ramasco and Morris, 2006). Wang and colleagues (2013) found a 3.34 average in- / out-degree in the study they conducted on the collaboration network of cancer research laboratories.

The main element in directed bilateral relations is how reciprocal the ties are (Hanneman and Riddle, 2005). When the ratio of reciprocal numbers in the health institutions is evaluated, it is seen that there are very little reciprocal linkages according to unilateral links. This may be related to the hierarchical structure of the institutions. In terms of comparison with the social network structure, Wang et al., (2016) found an arc of -3754 and reciprocity of 1.719 in the network of laboratory cooperative research involving 82 laboratories and 97 researchers. In our research, these rates were low in terms of reciprocal linkages.

When evaluating the clustering degree, it is more useful to evaluate the clustering coefficient compared to the overall density (Hanneman and Riddle, 2005). Both the cluster coefficient and the weighted cluster coefficient of the three health institutions in the study were higher than the general density of the institutions. Scientific cooperations, criminal organizations, friendship networks, etc. all networks are not identical qualitatively (Newman, 2001). For comparison, Wood's (2017) social network analysis on the smuggling network, it was found that the clustering coefficient was $c=0.801$, and the clustering coefficient of several cooperative and criminal network samples taken by Wood (2017) ranged from 0.442 to 0.638 . The clustering coefficient is $\mathrm{c}=0.66$ in distance education networks, $\mathrm{c}=0.69$ in complex 
networks, and $\mathrm{c}=0.48$ in information networks (Ramasco and Morris, 2006). According to this, the clustering coefficient of the health institutions in our research is lower. High clustering coefficients may indicate that members of the group tend to work together (Newman, 2001). However, in order for new relationships to be established, the group members may play an important role in ensuring mutual cooperation, which is why the network is overly bulky (Wood, 2017). In this sense, it can be said that the social network structure of health institutions is more dynamic.

The grade of a hierarchy in a population indicates "vertical differentiation". If an institution is fully hierarchical, it means that all the actors in the chart (except the top supervisor) have a node with a single supervisor (Hanneman and Riddle, 2005). Having mutual ties weakens the hierarchy. Taking the "0" value of the hierarchy can be explained by the fact that horizontal relations are more developed because of the fact that helping is an informal phenomenon even though the hierarchical structures are dominant in public health institutions. Connectedness and low LUB value can be explained by the fact that facilitation is an informal relationship. They show that there is no solid hierarchy in terms of helping. Efficiency values are relatively high when the number of actors in the network of institutions are taken into consideration. Higher efficiency values can be regarded as indicators of inefficiency in corporations. However, in structure of the scale developed by Krackhardt, efficiency is not considered to be a valid criterion for aid action because it is related to the hierarchical structure.

When we look at the transitivity indicators of the health institutions, although all transitivity indicators are relatively high in the health directorate, the network transitivity rate is highest in the hospitals union. The fact that transitivity indicators are high in the health directorate can be attributed to the fact that the largest number of actors is in this institution and therefore the number of relationships is high. It is stated that the small group theorists reveal that the most interesting and basic situation of the social structure is mostly related to the triplets. The existence and the prevalence of the triadic groups are fundamental elements of sociometry and social network analysis. The smallest social structure with the true character of society is the triadic groups. In the case of triadic groups, there may be tendencies (balance and transitivity) towards the consistency of balances and social structures (institutionalization). Triadic structures are the simplest structures in which the emergence of the hierarchy can be seen. For this reason, the transitivity of triadic groups is particularly emphasized in social network analysis (Hanneman and Riddle, 2005). In our study, the ratio of triadic groups of three institutions is between $40 \%-50 \%$. The research topic "helping" is not the official activity of employees. Thus, proportion of the triadic groups constitutes a good social structure for the relationship of cooperation in the institution.

When helping and cooperation maps of these three health institutions are examined, it is observed that there are isolated groups and a large number of pendants; a large number of brokerages that provide linkages between units or groups. The presence of isolated groups and pendants that are disconnected from the main group may suggest that there are constellations within the unit (Hanneman and Riddle, 2005). When it comes to helping in means of reciprocity, it is seen that there is much less mutual relief in the three health institutions, mostly involving unilateral helping. Brokerages seen in the health institutions provide a transition between other actors, showing structural gaps in institutions and social capital. Structural gaps and social capital may be comprised of having a strong support network or a privileged role, having an association or connection with a different social group or a person (Guzeller, 2016). Brokers know more about alternative ways of thinking and behaving, and benefit from their current position (Hanneman and Riddle, 2005; Burt, 2004). Typically, the most important nodes of a graph are centers with the highest number of links (Ramasco and Morris, 2006). At the same time, actors in the three health institutions in our research who are most asked for help in the network of helping are also at the center of the main mass. While determining the policies, it may be beneficial for health administrators to take the organizational (subgroups, brokerage actors, pendants, etc.) that have emerged in these mappings into consideration according to their purpose in institutions.

When the maps of helping network are examined according to the units of health institutions; it is seen that all three institutions first cooperated more intensively within the units; two other institutions except the health directorate provided cooperation with a few brokerage actors with little helping between the units. Especially, it seems that helping in the hospital is done in the units itself, and the relation of cooperation between the administrative units and the clinics is very little. It is seen that helping in administrative units is based on hierarchical network; middle and upper level administrators are asked for 
help above average. In clinics and isolated groups, there is a support at the horizontal level, and it seems that the colleagues along with the clinic chiefs and supervisors are at the forefront in assisting. In the hospitals union, especially middle-level managers (specialists) are employees who are asked most for help. Amabile et al., (2014) studied on helping relationships in Ideo, found that employees have a wide and diverse mutual helping structure that interacts with many people.

Except for the health directorate, the lack of helping among the units in other healthcare institutions overlaps with Mitzberg's professional bureaucracy configuration, which is found in organizations where employees with high levels of education are employed, units can work independently of each other, and which are more standardized in their skills (Mintzberg, 1979; Lunenburg, 2012). The higher clustering coefficient variable at the hospital may be related to the fact that the activities in the clinics are based on expertise. This supports Mitzberg's approach to professional bureaucracy.

It is seen that the helping relations of the employees in the health directorate occur among the units and between the employees; the equality of the helping in between employees and the administrative units overlap with the policy-making and strategy development functions of the health directorate. On the other hand, more helping occurs inside the units for the hospitals union and the hospital can be linked to the fact that they are implementing policies created by the higher institutions of these two institutions.

The helping relationship characteristics of the health directorate coincide with the helping relationship characteristics of the administrative units of the hospital. This similarity in relation to mutual helping can be explained by the similar work structure of the health directorate and administration of the hospital. As the health director must make quick and correct decisions while coordinating the provincial health service delivery, it is necessary for the hospital administration to act in a similar manner during health care delivery. It is natural that there are intense helping relations in this process.

In social network analysis, the common purpose of each variable is to explain the mechanisms and structural features of the network (Tuzunturk, 2012). When the ego network data of employees who are asked for help are examined according to the health institutions; in-degree, out-closeness, in-closeness, betweenness, size, pairs, reach efficiency, ego betweenness, and broker variables are higher in the health directorate than in the hospitals union and the hospital. The averages of the variables average distance and diameter are higher in the hospitals union than in the health directorate and the hospital. Within the three health institutions, the health directorate has the biggest ego neighbors and social relationships, the highest level of communication among the actors and most comfortable information exchange made among the employees. The average of average distance and diameter variables are higher in the hospitals union. It can be explained by the fact that the number of employees is small and the building they serve in at is smaller than the other health institutions. In addition, the health directorate and the hospital are much more established than the hospitals union, and the institutional structures are stronger.

According to the concept of similarity in social networking research, the social relations of actors with similar attitudes and qualities are more with each other. Individuals' basic characteristics such as gender, age, religion, education, occupation and social class, behavior, attitudes, competences, and beliefs strongly determine their relationships with others (McPherson et al., 2001). In health institutions similarity between those who asked for help and those who were asked for help has been examined by gender, age, education level, hierarchical level, work experience and seniority.

When the preferences of the employees for whom help were asked by their gender were examined; both male and female employees had asked for more help from male employees. Female employees are heterophilic, and male employees are homophilic. In other studies in the literature, it is stated that women are more willing to and more inclined to help (Punnett, 2011; Yildirim et al., 2006; Lee, 2002; Farrell and Finkelstein, 2007). When the preferences according to age are examined; a weak relationship was found at the health directorate and at the hospital among employees who asked for help and those who were asked for help. In the health directorate and at the hospital, employees under the age of 30 asked the most help from employees at the age of 30 and over while they asked for help at the very least from employees under the age of 30. In terms of age, employees below 30 years of age are heterophilic. Employees in all age groups have asked at the least help from employees under 30 years of age and at most from 30-39 years of age. 
When the similarities are examined according to educational level; employees with low level of education in the health directorate and the hospital asked help from employees with the low level of education while employees with higher education asked help from employees with the higher level of education. Employees with intermediate education are heterophilic, employees with low and high education are hemophilic. No significant difference was found in the hospitals union, according to educational level. When the similarities were examined according to hierarchical level; there was statistically significant difference in the all three institutions. Those who asked help at all levels have often asked for help from employees at hierarchical levels below their own levels.

When the similarities were examined according to the job experience; a weak relationship was found at the health directorate and at the hospital among the employees who asked help and those who were asked help. No significant difference was found in the hospitals union. At the health directorate and at the hospital employees who have 10-19 years of experience received have asked for the most help from employees who have 10-19 years of experience. Hence, employees who have 10-19 years of experience are homophilic. Employees who have job experience 10 years and less and those who have job experience of 20 years and more have asked help from the employees those who have job experience 10 years and more. Employees asked most for help from the employees who have 10-19 years of job experience (57.4\%). When the preferences of employees who asked for help were compared according to their tenure; only at the health directorate a weak relationship was found between the employees who asked for help and those who were asked for help.

In future studies, measuring helping and cooperation between employees in other sectors will show similarities and differences among sectors. Among the employees; measurement of information flow, subordinate relations and groupings can provide important contribution to health care managers. A network of helping and cooperation is important for managers to show informal relationships in the organization. For this reason, the examination of helping and cooperation relations at specific time intervals will be useful to show the administrators the change of informal structures in the institution. 


\section{APPENDIX}

For relationship ties between persons; single-sided relationships were drawn in blue; reciprocal relationships were drawn in red. Degree have been loaded to the nodes. There are three separate units in the hospital. Due to the fact that the hospital was a hospital affiliated with the hospitals union, yellow as a fourth coloration was made for the specialist group working within the hospitals union.

Hierarchical Levels
$\Delta($ Up triangle $)=$ Top Management
$\square($ Square $)=$ Middle Management
口 (Circle in a box) = Lower Management Directorate
$\circ($ Circle $)=$ Non-Managerial Employees Units Health

$\square$ (Pink) = Accrual and Financial Affairs Branch Directorate (BD)

$\square($ Claret red $)=$ Health Services Supervision BD

$\square$ (Orange) = Health Information Systems BD

$\square$ (Light green) = Surveillance and Evaluation BD

$\square$ (Light yellow) = Private Inpatient Health Services BD

$\square$ (Green) = Private Diagnostic and Treatment Centers BD

$\square$ (Light pink) = Public Inpatient Health Services BD

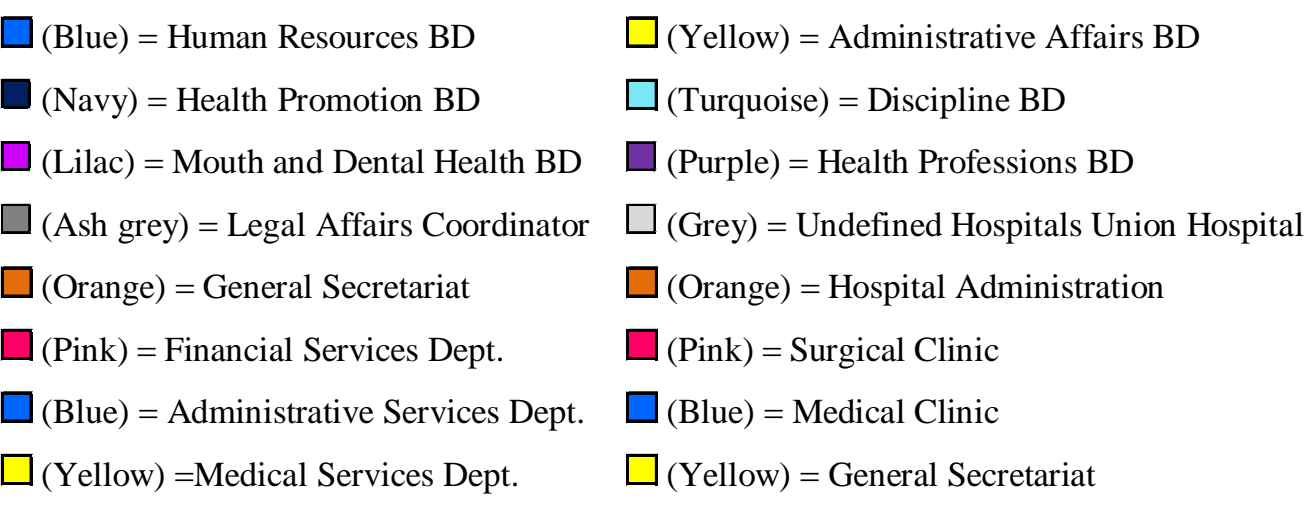

\section{FUNDING}

This research was supported by the Marmara University Scientific Research Projects Commission with project number: SAG-C-DRP-131016-0442. 


\section{REFERENCES}

Amabile, T., Fisher, C.M. and Pillemer, J. (2014), IDEO’s Culture of Helping, Harvard Business Review, January-February, pp. 1-9.

Ansell, C. and Gash, A. (2007), Collaborative Governance in Theory and Practice, Journal of Public Administration Research and Theory, 18 (4), pp. 543-571.

Behrendt, S., Richter, A. and Trier, M. (2014), Mixed Methods Analysis of Enterprise Social Networks, Computer Networks, 75, pp. 560-577.

Blau, P.M. (1964), Exchange and Power in Social Life, Transaction Books, John Wiley and Sons, New York.

Borgatti, S.P. (2002), Netdraw Network Visualization, Analytic Technologies, Harvard, MA.

Borgatti, S.P., Everett, M.G. and Freeman, L.C. (2002), Ucinet for Windows: Software for Social Network Analysis, Analytic Technologies, Harvard, MA.

Burt, R.S. (2004), Structural Holes and Good İdeas Source, American Journal of Sociology, 110 (2), pp. 349-399.

Carrington, P. J. (2014), Early Research in Social Networks, In: Dominguez, S., Hollstein, B., (Eds). Mixed methods social networks research: design and applications, Cambridge University Press, New York, pp. 38-39.

Cross, R., Borgatti, S.P. and Parker, A. (2002), Making İnvisible Work Visible: Using Social Network Analysis to Support Strategic Collaboration, California Management Review, 44 (2), pp. 25-46.

Daly, E. and Haahr, M. (2007), Social Network Analysis for Routing in Disconnected Delay-Tolerant MANETs, MobiHoc, 9 (1), pp. 32-40.

Denny, M. (2014), Social Network Analysis, Institute for Social Science Research, University of Massachusetts Amherst, 1-20. http://www.mjdenny.com/workshops/SN_Theory_I.pdf

Diestel, R. (2000), Graph Theory, Electronic Edition, 2. Edition, New York.

Emerson, R.M. (1976), Social Exchange Theory, Annual Review of Sociology, 2 (1), pp. 335-362.

Farrell, S.K. and Finkelstein, L.M. (2007), Organizational Citizenship Behavior and Gender: Expectations and Attributions for Performance, North American Journal of Psychology, 9 (1), pp. 81-96.

Faust, K. (2006), Comparing Social Networks: Size, Density, and Local Structure, Metodoloski Zvezki, 3 (2), pp. 185-216.

Freeman, L.C. (1996), Some Antecedents of Social Network Analysis, Connections, 19 (1), pp. 39-42.

Freeman, L.C. (2011), The Development of Social Network Analysis: With an Emphasis on Recent Events. http://moreno.ss.uci.edu/91.pdf

Guzeller, C.O., Eser, M.T. and Aksu, G. (2016), Social Network Analysis With Ucinet, Akademi Publications, Ankara.

Hanneman, R.A. and Riddle, M. (2005), Introduction to Social Network Methods, Riverside, CA: University of California, Riverside. http://faculty.ucr.edu/ hanneman/nettext/

Hansen, D., Shneiderman, B. and Smith, M.A. (2011), Analyzing Social Media Networks With NodeXL: İnsights from a Connected World, Morgan Kaufmann, Burlington.

Herz, A. and Petermann, S. (2017), Beyond interviewer Effects in the Standardized Measurement of EgoCentric Networks, Social Networks, 50, pp. 70-82.

Lee, F. (2002), The Social Costs of Seeking Help, The Journal of Applied Behavioral Science, 38 (1), pp. 17-35. 
Journal of Global Strategic Management | V. 11 | N. 2 | 2017-December | isma.info | 033-050 | DOI: 10.20460/JGSM.2018.251

Lunenburg, F.C. (2012), Organizational Structure: Mintzberg's Framework, International Journal of Scholarly, Academic, Intellectual Diversity, vol. 14, no. 1, pp. 1-8.

Matook, S. (2013), Conceptualizing Means end Chains of User Goals as Networks, Information and Management, vol. 50, pp. 24-32.

McPherson, M., Smith-Lovin, L. and Cook, J.M. (2001), Birds of a Feather: Homophily in social Networks, Annual Review of Sociology, vol. 27, pp. 415-444.

Mintzberg, H. (1979), The Structure of Organizations, Englewood Cliffs, NJ: Prenctice-Hall.

Molano, S. and Polo, A. (2015), Social Network Analysis in a Learning Community, Procedia Social and Behavioral Sciences, vol. 185, pp. 339-345.

Newman, M.E.J. (2001), Clustering and Preferential Attachment in Growing Networks, Phys. Rev. E, vol. 64, pp. 1-13.

Newman, M.E.J. (2003), Mixing Patterns in Networks, Phys. Rev. E, vol. 67, no. 026126, pp. 1-14.

Newman, M.E.J. (2010), Networks: an introduction, Oxford University Press, New York.

Ouellet, M., Bouchard, M. and Hart, M. (2017), Criminal Collaboration and Risk: the Drivers of Al Qaeda's Network Structure Before and After 9/11, Social Networks, vol. 51, pp. 171-177.

Perkins, J.M., Subramanian, S.V. and Christakis, N.A. (2015), Social Networks and Health: a Systematic Review of Sociocentric Network Studies in -Low and Middle- İncome Countries, Social Science and Medicine, vol. 125, pp. 60-78.

Provan, K.G. and Sebastian, J.G. (1998), Networks Within Networks: Service Link Overlap, Organizational Cliques, and Network Effectiveness, The Academy of Management Journal, vol. 41, no. 4, pp. 453-463.

Punnett, B.J.A. (2011), A Global Perspective on Gender and Organizational Culture, In: Ashkanasy N.M., Wilderom, C.P.M., Peterson, M.F. (Eds.), The handbook of organizational culture and climate, Second Edition, SAGE Publications, California, pp. 582-600.

Ramasco, J.J., Dorogovtsev, S.N. and Pastor-Satorras, R. (2004), Self-Organization of Collaboration Networks, Phys. Rev. E, vol. 70, pp. 1-10.

Ramasco, J.J. and Morris, S.A. (2006), Social İnertia in Collaboration Networks, Phys. Rev. E, vol. 73, no. 016122, pp. 1-7.

Tunali, V. (2016), Introduction to Social Network Analysis, Nobel Academic Publishing, Istanbul.

TLI. (2016), Contemporary Turkish dictionary. Turkish Language Institute.

http://www.tdk.gov.tr/index.php?option=com_gtsandarama=gtsandguid=TDK.GTS.5792755d50c2e1.393 61437

Tuzunturk, S. (2012), Network Science, Dora Publications, Bursa.

Wang, P., Robins, G., Pattison, P. and Lazega, E. (2013), Exponential Random Graph Models for Multilevel Networks, Social Networks, vol. 35, no. 1, pp. 96-115.

Wang, P., Robins, G., Pattison, P. and Lazega, E. (2016), Social Selection Models for Multilevel Networks, Social Networks, vol. 44, pp. 346-362.

Wood, G. (2017), The Structure and Vulnerability of a Drug Trafficking Collaboration Network, Social Networks, vol. 48, pp. 1-9.

Vacharkulksemsuk, T., Sekerka, L.E. and Fredrickson, B.L. (2011), Establishing a Positive Emotional Climate to Create 21st- Century Organizational Change, In: Ashkanasy N.M., Wilderom, C.P.M., Peterson, M.F. (Eds.). The handbook of organizational culture and climate, Second Edition, SAGE Publications, California, pp. 101-118. 
Journal of Global Strategic Management | V. 11 | N. 2 | 2017-December | isma.info | 033-050 | DOI: 10.20460/JGSM.2018.251

Yildirim, A., Aktas, T. and Akdas, A. (2006), Physician-Nurse Cooperation Faculty of Medicine and School of Nursing Students, TAF Preventive Medicine Bulletin, 5 (3), pp. 166-175. 